\title{
DO LITORAL AO SERTÃO: A ENERGIA EÓLICA NO ESTADO DA PARAÍBA
}

\author{
FROM THE COAST TO THE OUTBACK: WIND ENERGY IN THE STATE OF PARAÍBA
}

DEL LITORAL AL SERTÃO: LA ENERGIA EÓLICA EN EL ESTADO DE PARAÍBA

Ryan de Brito Cartaxo ${ }^{1}$

\begin{abstract}
Resumo
A energia eólica está em ascensão no Brasil, principalmente na Região Nordeste. Este artigo analisa os principais parques eólicos do estado da Paraíba, localizados em áreas geográficas distintas - litoral e sertão. Duas questões foram examinadas no estudo: quais os possíveis impactos ambientais dessas instalações e como a implantação desses parques pode contribuir para o contexto local. Esta pesquisa foi realizada a partir da análise de documentos oficiais, como relatórios, licenças concedidas e regulamentações. Tais documentos respaldaram as etapas de implantação e operação desses espaços e consideraram a legalidade das questões ambientais. Estes procedimentos foram complementados pelas falas dos moradores locais - a partir de questionários semiestruturados - e pelo exame da paisagem regional. Desta maneira, os principais impactos sentidos pelos habitantes no processo de implantação dos parques eólicos foram identificados.
\end{abstract}

Palavras-chave: Energia eólica. Fonte de energia renovável. Meio Ambiente. Paraíba.

\begin{abstract}
Wind power is on the rise in Brazil, mainly in the Northeast region. This article analyzes the main wind farms in the state of Paraíba, located in different geographic areas - the coast and the outback. Two questions were examined: what the possible environmental impacts of these facilities are and how the implementation of these wind farms can contribute to the local context. This research was carried out based on the analysis of official documents, such as reports, granted licenses and regulations. These documents supported the implementation and operation stages of these spaces and considered the legality of environmental issues. These procedures were complemented by the speeches of the local residents - from semi-structured questionnaires — and by the examination of the regional landscape. Hence, the main impacts felt by the inhabitants in the process of implementing wind farms were identified.
\end{abstract}

Keywords: Wind energy. Renewable energy source. Environment. Paraíba.

\section{Resumen}

La energía eólica está en ascenso en Brasil, sobre todo en la región noreste. Este artículo analiza los principales parques eólicos del estado de Paraíba, ubicados en zonas geográficas distintas — litoral y sertão. Dos cuestiones fueron examinadas en este estudio: cuáles son los posibles impactos ambientales de esas instalaciones y cómo la implantación de los parques puede contribuir para el contexto local. La investigación se realizó a partir del análisis de documentos oficiales, como informes, permisos otorgados y reglamentaciones. Tales documentos respaldaron las etapas de implantación y operación de esos espacios y afirmaron la legalidad de las cuestiones ambientales. Esos procedimientos fueron completados por informaciones de residentes locales — a partir de cuestionarios semiestructurados - y por el examen del paisaje regional. De esa forma, los principales impactos sentidos por los habitantes en el proceso de implantación de parques eólicos han sido identificados.

Palabras-clave: Energía eólica. Fuente de energía renovable. Medioambiente. Paraíba.

\section{Introdução}

\footnotetext{
${ }^{1}$ Mestre em Desenvolvimento e Meio Ambiente. E-mail: ryancartax@hotmail.com.
} 
A discussão sobre a produção de energia elétrica, por fontes alternativas no Brasil, tomou maior proporção a partir da crise ocorrida no setor em 2001. Essa emergência criou o maior racionamento de energia elétrica da história do país e foi causada pelo descompasso entre a capacidade instalada e o investimento em geração (LEME, 2009).

O perfil energético brasileiro é, majoritariamente, baseado em hidrelétricas. Todavia, esse cenário tem se modificado; mesmo não possuindo um número elevado, os parques eólicos começaram a fazer parte da produção de energia nacional, dentro de uma perspectiva de valorização de fontes renováveis. De maneira gradativa, a energia eólica adquire um papel relevante no Brasil, a partir das demandas energéticas pertinentes ao desenvolvimento sustentável (BRASIL, 2004).

Entretanto, a implantação de parques eólicos também se relaciona à questão dos licenciamentos e aos possíveis impactos causados não apenas ao meio ambiente, mas às comunidades locais, principalmente àquelas próximas às instalações.

Diante deste cenário, duas questões impulsionaram o desenvolvimento dessa pesquisa: como o licenciamento ambiental para implantação dos parques eólicos tem sido concedido no Brasil e no estado da Paraíba? Quais os impactos socioambientais causados pela construção desses parques eólicos?

O recorte geográfico se situa no estado da Paraíba. Foram analisados os parques eólicos Vale dos Ventos e Millennium, ambos localizados no município de Mataraca, que está a aproximadamente $110 \mathrm{~km}$ da capital João Pessoa/PB. Investigou-se, também, os parques: Canoas, localizado no Município de Junco do Seridó; Lagoa 1 em Santa Luzia; e Lagoa 2, situado entre os Municípios de São José do Sabugi e Santa Luzia, distantes 289 km de João Pessoa e separadas por 17,9 km entre os municípios citados.

Foram analisadas duas regiões distintas com características climáticas diferentes. O litoral é caracterizado por um clima mais úmido e chuvoso; no sertão, predomina o clima semiárido, com chuvas escassas. O estado da Paraíba vem se destacando em relação ao potencial eólico, tanto na Região Nordeste quanto no Brasil, devido às características climáticas e geográficas do território.

O número de projetos de energia eólica no estado da Paraíba tende a um crescimento constante, conforme demonstra a grande quantidade de empreendimentos em andamento; somente na região de Seridó, há a previsão de instalação de mais 135 aerogeradores. O arrendamento de terras para a construção dos geradores beneficia os moradores das áreas rurais e cria mais postos de empregos para a população local. Na fase de instalação, onde se demanda 
mais mão de obra, são abertas vagas nos mais diversos postos (fundação, construção das torres, limpeza de área, etc.).

\section{Materiais e Métodos}

2.1 Descrição da área de estudo

A Paraíba está localizada ao leste da Região Nordeste. Seu território está dividido em 223 municípios e apresenta relevo caracterizado por planícies, planaltos e depressões em forma de tabuleiros. Aproximadamente $90 \%$ da área está abaixo de $600 \mathrm{~m}$, com maiores elevações na região central do estado, mais especificamente na região do Planalto da Borborema, com elevações que variam de $400 \mathrm{~m}$ a $1197 \mathrm{~m}$.

De acordo com o Atlas Eólico da Paraíba (CERNE, 2016), foram analisados dados das antenas anemométricas espalhadas ao longo do seu território, a fim de atestar a viabilidade técnica e econômica para a implantação de parques eólicos no Estado. Os resultados apontaram as áreas potencialmente favoráveis à exploração dos recursos eólicos; 89\% dessas áreas estavam situadas no Planalto da Borborema, especialmente na microrregião do Seridó (oriental e ocidental).

$\mathrm{Na}$ mesorregião da Mata Paraibana, encontram-se dois empreendimentos em funcionamento: o Parque Eólico Vale dos Ventos e o Parque Eólico Millennium, ambos localizados no município de Mataraca, que está a aproximadamente $110 \mathrm{~km}$ da capital João Pessoa. A área é localizada entre Rio Tinto e Baía da Traição, que é fronteira "litorânea" entre os estados da Paraíba e Rio Grande do Norte (MATARACA, 2017).

Um empreendimento pioneiro no estado, o Parque Eólico Millennium pertence à empresa Pacific Hydro Brasil e começou a operar no ano de 2007. Esse empreendimento está em um local que oferece excelentes condições para a instalação de aerogeradores: vasta área costeira, incidência de ventos fortes, fácil acesso para veículos e máquinas e pronta conexão com a rede elétrica. Essa região está localizada nos limites entre a Paraíba e o Rio Grande do Norte, às margens do Rio Guajú, que separa os dois estados.

O parque conta com 13 aerogeradores e apresenta capacidade instalada de 10,2 MW energia suficiente para abastecer 24.000 residências brasileiras —, deixando de emitir em torno de 9.492 toneladas de gases de efeito estufa por ano. O local opera sob Certificação da Norma Internacional ISO 14001, que promove projetos de mitigação de impactos ambientais causados pela atividade. Essa energia limpa produzida pelo Parque Eólico Millennium é destinada à 
Eletrobrás, empresa responsável pela geração, transmissão e distribuição da energia produzida no Brasil.

Os investimentos para instalação do Parque Eólico Millennium totalizam, aproximadamente, $\mathrm{R} \$ 42,9$ milhões. O montante foi garantido pelo Programa de Incentivo às Fontes Alternativas de Energia Elétrica (PROINFA) do governo federal, através do financiamento do Banco do Nordeste do Brasil (BNB), que possui foco especial no setor de energia renovável — incluindo projetos de energia eólica.

O Parque Eólico Vale dos Ventos, localizado no município de Mataraca, litoral norte da Paraíba, pertence à empresa australiana Pacific Hydro Brasil. Sua construção teve início em 2007, mas as instalações só entraram em operação no ano de 2009; elas são compostas por 60 turbinas eólicas, ou aerogeradores, de 800KW, com uma geração anual de energia de 119 GWh. Essas turbinas estão instaladas em cinco propriedades particulares, ocupando uma fração de 5\% das terras. Sua produção total corresponde a 5\% da energia gerada no Estado (PACIFIC HYDRO, 2018).

O Parque Eólico Vale dos Ventos possui um tempo de vida útil de 50 anos; ao completar 25 anos, as instalações serão submetidas a uma reavaliação e manutenção geral. Instaladas a 200 metros de distância uma da outra, as torres de concreto do parque possuem 80 metros de altura e hélice de fibra e metal com 48 metros de diâmetro; a base mede 20×30 metros, com área de 7.963,95 m². Os aerogeradores estão instalados em uma área de cultivo de cana-deaçúcar e de pecuária, em que uma atividade econômica não interfere no desempenho da outra.

Outros empreendimentos eólicos são os parques de Canoas, Lagoa 1 e Lagoa 2, que estão localizados em três municípios do sertão do estado - São José do Sabugi, Santa Luzia e Junco do Seridó - , a uma distância de 289 km da capital João Pessoa. Tendo em vista que as instalações desse complexo foram implantadas simultaneamente, cabe uma análise unificada de suas particularidades.

Algumas empresas que atuam em diversas partes do mundo, inclusive no Brasil, perceberam as potencialidades presentes no Vale do Sabugi, na Paraíba. Considerando os ventos fortes que sopram na área, essas empresas optaram por investir na região; há, além disso, a expectativa da ampliação desses investimentos em um curto espaço de tempo.

Com uma projeção de crescimento de $2 \mathrm{GW}$ naquela região, estima-se que o local pode atingir níveis de desenvolvimento similares ao polo de geração eólica de João Câmara, no estado vizinho do Rio Grande do Norte.

Após uma série de estudos realizados pela empresa supracitada e através das informações obtidas das torres anemométricas instaladas pela região, decidiu-se investir na 
construção do complexo eólico de Santa Luzia (Canoas, Lagoa 1 e Lagoa 2). O direito à construção da instalação foi negociado no Leilão de Energia Nova A-5, realizado em 28 de novembro de 2014. À época, o lance foi de R\$ 136,24/MWh; em valores atualizados, R\$ 167/MWh (ANEEL, 2014).

O investimento total dos projetos foi de, aproximadamente, $\mathrm{R} \$ 604$ milhões. Desse montante, R \$ 331 milhões se referem a empréstimos de longo prazo junto ao BNDES e R \$ 46 milhões via títulos de créditos; o restante do valor é aporte de capital próprio da companhia, por meio do ativo de cada acionista. (ANEEL, 2014)

Os parques contam com 45 aerogeradores da marca Gamesa, modelo G114, com 80 metros de altura e 2,1 MW de capacidade de geração. Na fase de instalação, o empreendimento gerou, aproximadamente, 510 empregos diretos e indiretos, além da valorização da mão de obra regional.

As áreas dos aerogeradores ocupam quatorze propriedades, distribuídas nos três municípios e as cotas vão de 440m a 700m, acima do nível do mar.

$\mathrm{Na}$ fase de instalação ocorreram melhorias nas vias que dão acesso aos parques, com o objetivo de facilitar o transporte das peças e equipamentos necessários à montagem dos aerogeradores e subestação do complexo. Primordiais na fase de instalação, tais vias seguem com a mesma relevância nos dias atuais. Os benefícios gerados pela obra não são exclusivos do Complexo, mas ficam disponíveis para uso de toda a população - principalmente para os moradores das comunidades no entorno dos parques.

Dentro do contexto do complexo eólico Santa Luzia, a empresa Força Eólica do Brasil (FEB) administra os três parques em atividade até o momento:

- Parque Eólico Canoas: possui 15 turbinas eólicas, com potencial nominal de 2 MW, totalizando, em média, 30 MW de potência instalada; o parque está localizado nos municípios de São José do Sabugi e Junco do Seridó, no estado da Paraíba;

- Parque Eólico Lagoa I: possui 15 turbinas eólicas, com potencial nominal de 2 MW, totalizando, em média, 30 MW de potência instalada; esse parque também está localizado nos municípios de Santa Luzia e São José do Sabugi;

- Parque Eólico Lagoa II: possui 15 turbinas eólicas, com potencial nominal de 2 MW, totalizando, em média, 30 MW de potência instalada; esse empreendimento está localizado no município de São José do Sabugi.

Com o melhoramento da infraestrutura para a instalação dos parques e dos aerogeradores, estes não ocupam nem $10 \%$ das propriedades; além disso, tais modificações não prejudicaram o desenvolvimento das atividades locais (pecuária e agricultura). 
Os empreendimentos eólicos localizados no estado da Paraíba foram licenciados pela Superintendência Administrativa do Meio Ambiente (SUDEMA). Todas as iniciativas se submeteram às seguintes fases: Licença Prévia (LP), que corresponde à primeira etapa de análise sobre a viabilidade ambiental e principais requisitos a serem cumpridos; Licença de Instalação (LI), que é uma autorização emitida após a avaliação estabelecida durante a LP, com medidas de proteção ambiental já definidas; Licença de Operação (LO), que dita as regras de funcionamento do empreendimento após o cumprimento das exigências anteriores. Estas fases são necessárias para a obtenção da licença ambiental; neste aspecto, todas as empresas cumpriram os requisitos exigidos, além de manter total observância quanto às suas respectivas condicionantes.

\subsection{Metodologia}

Esta pesquisa possui natureza qualitativa e se baseia em um estudo de campo. A partir de visitas in loco nas regiões dos parques eólicos, observou-se o processo de ocupação e seus impactos no meio ambiente e na comunidade local. A implantação dos parques eólicos foi estudada a partir de duas abordagens: meios legais e técnica. As entrevistas possibilitaram a análise das falas dos moradores locais, que foram os principais sujeitos atingidos pelas mudanças causadas pelos empreendimentos eólicos.

Além disso, foi realizada uma revisão bibliográfica e documental, com o objetivo de embasar a discussão através da análise dos documentos oficiais. Foram utilizadas, também, produções científicas como artigos, teses, dissertações e livros.

Dentre as principais fontes analisadas na fase de Licença Prévia de parques eólicos, dois documentos se destacaram: o relatório ambiental simplificado e a certidão de uso e ocupação do solo.

A análise dos itens descritos nas condicionantes estabelecidas pela SUDEMA, bem como dos Relatórios Técnicos — provenientes dos processos de licenciamento ambiental dos parques eólicos no Estado da Paraíba —, foram advindas das visitas feitas à Central de Documentação-CDOC. O acesso aos documentos físicos e digitalizados foi possibilitado pelo deferimento de um pedido de autorização por escrito, que foi direcionado ao superintendente da SUDEMA. Após esses procedimentos, a análise do material disponibilizado pelo órgão foi realizada.

Através de entrevistas semiestruturadas, realizadas com moradores e lideranças comunitárias que vivem no entorno dos parques eólicos, tanto os localizados no litoral, quantos 
os localizados no interior do estado, confirmou-se que os empreendimentos exercem atividades de caráter socioambiental em suas localidades.

\section{Resultados e Discussões}

Após a crise no setor energético nacional, ocorrida em 2001, que revelou um grave problema estrutural no qual a oferta de eletricidade por hidrelétricas não supria totalmente a demanda, foi necessário repensar o planejamento do setor elétrico, onde a participação do Estado foi fundamental para desenvolver políticas de incentivos, financiamentos e investimentos, além de buscar parcerias estratégicas com o setor privado. (GAVINO, 2011; DUTRA, 2001)

Nesse contexto, surgiu o Programa Nacional de Incentivo a Fontes Alternativas de Energia (PROINFA), em 2002, que foi um importante marco para a sustentabilidade na geração de energia no Brasil. Desde então, iniciou-se a participação da produção da Energia Eólica na sua matriz energética.

Com o desafio de promover a participação de fontes alternativas de energia renovável, na produção de energia elétrica no Brasil, surge o PROINFA, através da criação da Lei $n^{\circ}$ 10.438/2002. Priorizou-se, com essa criação, empreendimentos que não apresentam vínculos com empresas que atuem na geração, transmissão ou distribuição de energia.

O Brasil é um dos principais países em expansão dessa fonte eólica de energia e ocupa a oitava posição do ranking dos países com maior capacidade instalada. Em 2017, o país possuía 508 usinas eólicas com capacidade instalada total de aproximadamente $13 \mathrm{GW}$. O país tem hoje 15GW de capacidade instalada, em mais de 600 parques e mais de 7.000 aerogeradores em operações em 12 estados — de acordo com dados do boletim mensal da Câmara de Comercialização de Energia Elétrica (2018) e pela ABEEólica (2019).

A Região Nordeste se destaca quanto aos números de usinas eólicas no país. O estado do Rio Grande do Norte, por exemplo, ocupa a primeira posição em relação à capacidade instalada com 4.066,15 MW, seguido pelos estados da Bahia e Ceará, com respectivamente, 3.934,99 MW e 2.045,46 MW.

Do total de $15 \mathrm{GW}$ de capacidade instalada no país, a região Nordeste corresponde a 86\%. De acordo com dados divulgados pela ABEEólica em 11 de abril de 2019, a distribuição da capacidade instalada corresponde à: 
Tabela I - Capacidade instalada de energia eólica nos estados da Região Nordeste

\begin{tabular}{|l|l|l|}
\hline Estado & Potência $(\mathbf{M W})$ & $\mathbf{N}^{\mathbf{0}}$ de parques \\
\hline RN & $4.066,15$ & 151 \\
\hline BA & $3.934,99$ & 153 \\
\hline CE & $2.045,46$ & 79 \\
\hline RS & $1.831,87$ & 80 \\
\hline PI & $1.638,10$ & 60 \\
\hline PE & 781,99 & 34 \\
\hline MA & 328,80 & 12 \\
\hline SC & 238,50 & 14 \\
\hline PB & 157,20 & 15 \\
\hline SE & 34,50 & 1 \\
\hline RJ & 28,05 & 1 \\
\hline PR & 2,50 & 1 \\
\hline Total & $\mathbf{1 5 . 0 8 8 , 1 0}$ & $\mathbf{6 0 1}$ \\
\hline
\end{tabular}

Fonte: ABEEÓLICA, 2019

Por dispor dos melhores ventos do mundo, o que propicia uma produtividade que chega a ser o dobro da média mundial, essa região possui uma "safra de vento" intensa — no período que vai de junho a novembro. Uma média mensal, o fator capacidade mundial gira em torno de $25 \%$, e no período de "safra", no Nordeste, pode ultrapassar os $60 \%$ e $70 \%$, nesse último nos casos de recorde.

Segundo a presidente da ABEEólica, Elbia Gannoum (2018), a região Nordeste vem se sobressaindo em relação às outras regiões do país, apresentando a cada dia novos números. Esses números batem recordes de participação no Sistema Integrado Nacional (SIN), atingindo 13\% no mês de julho de 2018, de acordo com o Boletim Mensal de Dados da ONS. A respeito desses percentuais, Gannoum (2018) reforça que:

No caso específico do Nordeste, os recordes de atendimentos de carga já ultrapassam o 70\%. O dado mais recente de recorde da região é do dia 13 de setembro, uma quintafeira, quando $75 \%$ da demanda foi atendida pela Energia Eólica, com geração média diária de 7.716 Mwmed e fator de capacidade de 77\%. Vale mencionar que, neste mesmo dia, houve uma máxima às $8 \mathrm{~h} 24$, com $83 \%$ de atendimento da demanda e $87 \%$ de fator de capacidade e o Nordeste foi exportador de energia durante todo dia.

Diante do potencial da região Nordeste, devido aos fatores que contribuíam para a implantação da energia eólica, várias instituições se empenham no mapeamento eólico, 
principalmente ao longo da Costa Atlântica, onde se observam fortes e constantes ventos praticamente durante todo o ano.

A energia eólica por ser considerada uma "energia limpa" de fonte renovável, já apresenta características positivas do ponto de vista dos impactos ambientais. Além disso, alguns outros fatores são avaliados como positivos, entre eles: redução da emissão de gases do efeito estufa; desenvolvimento local e acesso à energia.

No fator desenvolvimento local, as contribuições sociais são as mais efetivas, principalmente no investimento em projetos educacionais voltados à qualidade de vida dos estudantes da rede pública de ensino, em que ações de cidadania, capacitação, educação ambiental são fatores de debates. Somado a isto, há o incentivo ao artesanato local, com foco no desenvolvimento econômico, inclusão digital, incentivo ao turismo, fortalecimento da produção das cadeias locais. Essas ações são voltadas, também, para saúde e o esporte.

Os empreendimentos eólicos favorecem também o aquecimento da economia local, através da absorção de mão de obra, principalmente na fase de implantação dos parques, o que aumenta a renda das pessoas. Ressaltamos, também, que a maioria dessas pessoas é de baixa renda.

Nessa perspectiva, pode-se identificar, nas falas dos sujeitos entrevistados, alguns dos fatores positivos. Um exemplo é a fala de um dos entrevistados, morador de Barra de Camaratuba, no litoral. Ao ser indagado sobre as contribuições do ponto de vista social que os parques trouxeram à comunidade, respondeu que: "todo mês vem umas pessoas dar aula de corte e costura aqui na associação, aulas de saúde alimentar e palestras sobre meio ambiente nas escolas". (SUJEITO 1, MATARACA, 2018)

Outro fator de melhora foi a construção de estradas que dão acesso às praias de Sagi e Barra de Camaratuba. As estradas não tinham nenhum tipo de pavimentação, eram cheias de buracos e apresentavam vários pontos de erosão, devido às fortes chuvas na região; além desses fatores citados, havia a movimentação intensa dos caminhões e treminhões, tendo em vista as atividades econômicas provindas do cultivo extenso da cana-de-açúcar e a extração de minério.

O mesmo processo ocorreu no interior do estado. Segundo um morador de São José do Sabugi, a implantação do Parque Eólico na sua região possibilitou "o melhoramento das estradas, beneficiaram os morados das comunidades e facilitaram o acesso as cidades mais próximas" (SUJEITO 1, MATARACA, 2018). Ou seja, a reestruturação das rodovias para melhor acesso dos veículos de serviços aos parques, torna-se um benefício coletivo, pois atende as demandas de deslocamentos locais com uma maior qualidade. É importante ressaltar que essa foi uma questão recorrente entre os entrevistados. 
Em relação à valorização das terras, muitos entrevistados afirmaram que com a presença dos parques, moradores deixaram de migrar para outras regiões do estado, devido à valorização que suas terras tomaram. Segundo um representante da Associação dos Produtores Rurais de Santa Luzia, a valorização da terra, que pulou de $R$ \$ 200,00 o hectare para $R$ \$2.000, além da regularização fundiária, em que a empresa assume os custos junto aos cartórios e prefeituras antes de firmarem os contratos de arrendamento.

Os valores pagos pela empresa aos proprietários que possuem aerogeradores instalados em suas terras, é outro tópico citado. Conforme relato do morador da comunidade do Pinga em Santa Luzia, "com o arrendamento das terras, cada proprietário recebe $\mathrm{R} \$ 600,00$. Caso tenha acima de 100 hectares, recebe a mais R\$2,00 por hectare". Isso para os que tem torres de medição instaladas em sua propriedade. "Para os que tem aerogeradores instalados em sua propriedade recebe $1 / 2 \%$ do valor da energia gerada para cada parque, e são divididos pelos proprietários" (SUJEITO 2 MATARACA, 2018). Ou seja, cada proprietário, além dos rendimentos provenientes das atividades agrícolas ou benefícios de aposentadoria, por exemplo, recebe por mais uma fonte, a energia eólica.

Isto gerou novas expectativas nos sertanejos daquela área, que viram a possibilidade de continuarem em suas propriedades. Eles teriam, também, mais capacidade para investir na atividade agropecuária, através da aquisição de equipamentos, insumos e máquinas, com o objetivo de aumentar a produtividade; logo, suas rendas per capta melhorariam.

Com a vinda dos empreendimentos eólicos para essas regiões, tanto no litoral como no sertão, houve um aumento na movimentação da economia local, principalmente nas sedes das cidades, a exemplo de Santa Luzia, São José do Sabugi e Junco do Seridó.

Em relação ao desenvolvimento econômico, alguns setores se destacaram, como o setor imobiliário. Exemplos de desenvolvimento foram: os aluguéis temporários - para abrigarem os trabalhadores que vinham de outras localidades —, restaurantes, postos de combustíveis, supermercados, entre outros. Além da absorção de mão de obra local, principalmente na fase de implantação dos parques, a renda per capta dos moradores foi elevada.

Observa-se que algumas empresas de consultoria no setor de energias renováveis se instalaram na cidade de Santa Luzia, o que desenvolveu uma rede de serviços para dar suporte técnico aos parques eólicos; assim, aumentou-se a carga tributária nos municípios.

Consequentemente, com o aumento na renda per capta, ocorreu uma melhora na expectativa de viva dos moradores, principalmente em relação às perspectivas de desenvolvimento da região; um exemplo desse panorama foi a possibilidade de instalarem unidades educacionais tecnológicas, com cursos de níveis técnico e tecnológico, na área de 
energias renováveis. Além disto, os filhos dos moradores locais, que tivessem interesse de estudar em outros lugares, obtiveram a oportunidade de uma melhor formação e qualificação profissional. Isto aconteceu na Cidade de João Câmara, no estado vizinho do Rio Grande do Norte, após a chegada do Polo de Energia Eólica.

Diante do aumento dos tributos municipais, advindos do recolhimento de impostos das empresas do setor eólicos, houve uma melhoria na infraestrutura das cidades, maiores condições de investimentos em educação, saúde, cultura e lazer para a população.

De maneira geral, constata-se que a percepção dos moradores em relação à energia eólica é positiva. Os moradores demonstraram ter ciência dos seus impactos positivos; todavia, é perceptível nas falas a expectativa de um desenvolvimento econômico local mais efetivo, em que a mão-de-obra da região possa vir a ser utilizada, pois eles relatam que os benefícios maiores estão sendo em prol dos empresários e não da comunidade. Os habitantes afirmam, também, que são afetados por alguns impactos negativos.

A atividade eólica, apesar de toda inovação tecnológica, apresenta características ambientais desfavoráveis, por exemplo: impacto visual, ruído, interferência eletromagnética, supressão vegetal, ofuscamento e danos à fauna. Porém mediante um planejamento adequado, esses impactos podem ser minimizados ou até mesmo eliminados com o uso de novas tecnologias. (DUTRA, 2001)

Dentre estes impactos, alguns foram mais recorrentes nesta pesquisa sendo eles: impacto sobre a fauna e avifauna; ruído; impacto visual; supressão da vegetação e desmatamento das áreas de dunas.

A maior preocupação relativa à fauna é com os pássaros, os quais podem chegar a colidir com estruturas das turbinas eólicas. O problema pode se intensificar quando os aerogeradores são instalados em rotas migratórias de determinadas espécies. Pode ocorrer, também, a alteração do habitat dos pássaros, com a degradação do ambiente — o que altera os locais de pouso, nidificação, reprodução, alimentação e rotas migratórias.

Em regra, para a mitigação deste impacto, é realizado um estudo prévio nas áreas previstas para implantação do empreendimento onde são observados o comportamento da fauna terrestre e avifauna, sobretudo na quiropterofauna, espécies ameaçadas de extinção, aves de rapina. Isso irá subsidiar ações para minimizar os impactos impostos na instalação dos empreendimentos.

O ruído provocado pelas turbinas eólicas é do tipo mecânico de engrenagem e geradores, assim como aerodinâmico ocasionado pelas pás. Este problema tem amenizado pelos materiais 
de isolamento, o que reduz os barulhos. Entretanto, os projetos mais recentes já possuem um formato que possibilita a otimização, com o objetivo de reduzir o ruído aerodinâmico.

Em uma das visitas aos parques eólicos, utilizou-se um aplicativo chamado Decibelímetro (Sound Meter). É importante ressaltar que esse aparelho não checa com tanta precisão como um decibelímetro profissional, porém foi utilizado a fim de obter uma média dos níveis sonoros emitidos pelos aerogeradores. Na chegada, registrou-se níveis entre $68.5(\mathrm{~dB})$ e 72,8 (dB); contudo, esses números se referem ao ruído do ambiente, pois, o sopro do vento interfere nos sons emitidos pelo movimento das pás.

As transformações visuais, tendo em vista a mudança da paisagem com a implantação dos aerogeradores, são as que causam o chamado primeiro impacto. "Os impactos variam muito de acordo com o local das instalações, o arranjo das torres e as especificações das turbinas. Apesar dos efeitos negativos, esses impactos tendem a atrair turistas". (LUCRECIO et al., 2010, p. 27)

Sobre a paisagem, os moradores relatam que até acharam "mais bonito" com os aerogeradores. Os habitantes ressaltam, ainda, que houve um leve aumento no turismo, pois, as pessoas se deslocavam para conhecer os parques eólicos.

Podemos considerar que o impacto visual possui um caráter subjetivo para as pessoas. Algumas pensam que as turbinas eólicas são agradáveis na paisagem e compõe de maneira positiva o ambiente, enquanto outros têm opiniões opostas. Pesquisas relevantes mostraram que mais de $70 \%$ das pessoas não têm uma opinião negativa sobre turbinas eólicas. (LIMA et al., 2015)

A supressão da vegetação, assim como o desmatamento da área de Dunas, acontece durante as fases de construção e permanência do empreendimento ou sua exploração, tendo como impactos recorrentes a supressão da vegetação (gerando supressão de ambiente com fauna e flora e a fragmentação local dos ecossistemas relacionados), remoção de terra e compactação dos terrenos por máquinas.

Sobre os impactos ambientais dos parques eólicos, os entrevistados descreveram que no início da construção foram retiradas uma boa parte da vegetação local para a instalação das torres e abertura de novas vias de acesso.

Com relação aos impactos ambientais causados pelo funcionamento dos parques eólicos no estado da Paraíba, observou-se que as empresas buscam mitigar os danos ao meio ambiente com a aplicação de programas de monitoramento da vegetação, da fauna, bem como, na aplicabilidade dos programas socioambientais junto às comunidades de entorno dos parques. 
Compreende-se que muitas dessas ações são realizadas apenas para cumprir os itens contidos nas condicionantes de suas respectivas licenças ambientais.

\section{Considerações finais}

A discussão em torno da energia eólica se reflete em diversas perspectivas. No que tange ao discurso social e ambiental, garante-se que a energia eólica é uma energia limpa, por oferecer baixo potencial poluidor e promover a sustentabilidade ambiental. Afirma-se, também, que a energia eólica por ser uma energia limpa, oferece condição de vulnerabilidade para a população, por não perceber a dimensão dos impactos negativos, tanto no meio social quanto no meio físico-biótico, ocasionadas pela implantação desses parques.

Em contato com os Relatórios Ambientais Simplificados, apresentados pelos empreendimentos, como requisito indispensável no processo de Licença Prévia (LP) de parques eólicos na SUDEMA, observa-se que os conteúdos descritos nesses estudos são considerados satisfatórios. Eles abordam de maneira detalhada, vários aspectos relacionados ao meio ambiente, nos locais pretendidos para instalação dos empreendimentos eólicos; apresentam-se, ainda, informações relacionadas ao meio físico-biótico, como a fauna, flora, clima, solo, hidrografia, além dos conteúdos de caráter social, como: população, economia, cultura, arqueologia e educação.

Sobre as condicionantes descritas nas licenças ambientais de parques eólicos emitidas pela SUDEMA, constatou-se a existência de vários itens relacionados à preservação, recuperação e manutenção do meio físico-biótico. Porém, quanto aos aspectos sociais, não se identificou, nas condicionantes da LP, LI e LO, elementos 76 que abordassem as comunidades do entorno do parque - que é uma exigência ao funcionamento desses empreendimentos.

Para que o desenvolvimento sustentável seja efetivo, no seu amplo sentido, espera-se que, com a inserção da energia eólica na matriz energética brasileira, em especial no estado da Paraíba, os aspectos seguintes sejam cumpridos: fatores ambientais, sociais e econômicos, vinculadas às exigências das licenças ambientais (LP, LI e LO), ou pelo RAS ou EIA/RIMA.

Com relação ao processo de identificação dos possíveis impactos ambientais ocasionais com a instalação dos parques eólicos, compreende-se que os moradores do município de Mataraca-PB, já se adaptaram a presença dos aerogeradores, pois convivem com eles há mais de dez anos, desde 2007. Segundo relatos, a energia eólica trouxe benefícios, principalmente na fase de implantação dos parques, quando foram empregados muitos moradores nas obras de construção, abertura de vias e na limpeza das áreas. 
Nos dias atuais, poucas pessoas da comunidade de Barra de Camaratuba trabalham nos parques, em torno de 4 a 6 funcionários apenas, o que gera certo anseio na população local. Os Parques Eólicos de Mataraca, Vale dos Ventos e Millennium estão inseridos em grandes fazendas de cana de açúcar. Isso foi um obstáculo para a pesquisa, pois não obtivemos nenhuma informação quanto aos contratos de arrendamento das frações de terras, firmados pelos parques com os proprietários, já que se trata de grandes latifúndios, amplamente comprometidos com a produção agroindustrial.

Quanto aos pequenos agricultores, eles não possuem aerogeradores em suas terras. Já em relação aos programas socioambientais implantados pelos empreendimentos eólicos Vale dos Ventos e Millennium junto as comunidades, são efetivamente executados mediante concursos. Esses concursos são publicados periodicamente em editais em seus sites oficiais, para selecionar, entre diversos projetos, o que mais apresenta viabilidade para as comunidades.

Além disto, são fornecidos apoio a algumas ONGs, como a que atua na proteção e preservação do caranguejo Uçá, na Barra de Camaratuba. Desta forma, concluímos que os empreendimentos localizados no litoral paraibano participam ativamente no cotidiano dessas comunidades.

A perspectiva dos moradores em relação à energia eólica se solidificou com a implantação dos parques em suas regiões; contudo, pode-se identificar nas suas falas um conhecimento prévio sobre esse tipo de energia, ou seja, muitas pessoas já tinham ouvido falar, porém sem contato.

Foi possível compreender que os moradores, apesar de demonstrarem preocupação com relação aos impactos ambientais provenientes da instalação dos parques eólicos principalmente quanto a supressão vegetal —, são favoráveis a este tipo de energia. Essa visão positiva ocorre em decorrência da comparação com outras formas de geração de energia (como a hidráulica por exemplo), pois, a energia eólica traz menos impactos aos moradores da região dos empreendimentos.

Neste cenário de crescimento na produção de energia eólica no estado da Paraíba, destacam-se duas realidades diferentes, entre os moradores dos municípios do litoral e do sertão. Os moradores de Mataraca-PB, por exemplo, demonstraram ter incorporado no seu cotidiano uma relação harmônica com os parques eólicos Millennium e Vale dos Ventos.

Foi possível perceber essa relação na rotina das pessoas que trabalham no plantio e na colheita da cana-de-açúcar, como nos pescadores que atravessam as trilhas existentes dentro dos parques que dão acesso ao mar, nos pequenos agricultores, nos moradores das comunidades de Barra de Camaratuba e Barra do Guajú, até mesmo nos visitantes que buscavam lazer nesses 
lugares. Isso demonstra que estes sujeitos acreditam no impacto positivo que a energia eólica pode causar.

Com relação aos moradores dos municípios de Junco do Seridó, São José do Sabugi e Santa Luzia, houve em um primeiro momento, insegurança; contudo, o que se identifica é que a falta de conhecimento sobre a energia eólica, o que gera um sentimento de resistência em alguns. Entretanto, para a maior parte dos moradores entrevistados, essa atividade gera prosperidade, principalmente para os moradores das zonas rurais — onde estão instalados os aerogeradores.

Quanto ao compromisso da empresa responsável pelos parques eólicos Canoas, lagoa 1 e Lagoa 2, pode-se afirmar que são realizadas diversas ações de cunho social e ambiental junto as comunidades locais. Entre essas ações, estão: atividades de educação ambiental nas escolas municipais e associações de moradores; programas de monitoramento da avifauna local; manutenção das vias de acesso aos parques que contemplam os moradores das áreas rurais próximas aos parques; monitoramento das águas dos poços e riachos localizados na área de influência do complexo eólico; programas de contenção do solo; e recuperação vegetal de áreas degradadas.

\section{Referências}

ABEEÓLICA- Associação Brasileira de Energia Eólica. Boletim anual de geração. 2019. Disponível em: http://abeeolica.org.br/wp-content/uploads/2020/06/PT_Boletim-Anual-deGera\%C3\%A7\%C3\%A3o-2019.pdf. Acesso em: 25 out. 2020.

AESA. Caracterização do clima, da pluviometria e da fluviometria. 2016. Disponível em: http://www.aesa.pb.gov.br/aesa-website/wp-content/uploads/2016/11/PE_10.pdf. Acesso em: 23 jan. 2019.

ALVES, J. J. A. Estimativa da potência, perspectiva e sustentabilidade da energia eólica no estado do Ceará. 163f. Tese (Doutorado em Recursos Naturais) - Pós-Graduação em Recursos Naturais, Universidade Federal de Campina Grande, Campina Grande, 2006.

ANEEL- Agência Nacional de Energia Elétrica. Banco de Informações de Leilões. 2014. Disponível em: http://www2.aneel.gov.br. Acesso em: 28 out. 2020.

BARRADAS, R. V. Impactos socioambientais nas aplicações de energia eólica para geração de eletricidade. Lavras: UFLA, 2014.

BRASIL. Manual do Licenciamento Ambiental: Guia de procedimento passo a passo. 2004. Disponível em: http://www.mma.gov.br/estruturas/sqa_pnla/_arquivos/cart_sebrae.pdf. Acesso em: 12 nov. 2018. 
BRASIL. Cartilha de Licenciamento Ambiental. 2007. Disponível em: http://www.mma.gov.br/estruturas/sqa_pnla/_arquivos/cartilha.de.licenciamento.ambiental.se gunda.edicao.pdf. Acesso em: 20 jan. 2019.

CERNE - Centro de estudos de energias renováveis. Atlas Eólico da Paraíba. 2016. Disponível em: http://cerne.org.br/atlas-eolico-da-paraiba-esta-disponivel-para-download/. Acesso em: 20 nov. 2018.

CONAMA- Conselho Nacional do Meio Ambiente. Resolução 01/1986. Disponível em: https://www.ibama.gov.br/sophia/cnia/legislacao/MMA/RE0001-230186.PDF. Acesso em: 21 out. 2018 .

CONAMA- Conselho Nacional do Meio Ambiente. Resolução 237/1997. Disponível em: http://extwprlegs1.fao.org/docs/pdf/bra25095.pdf. Acesso em: 20 out. 2018.

CONAMA- Conselho Nacional do Meio Ambiente. Resolução 2790/2001. Disponível em: http://www2.mma.gov.br/port/conama/res/res01/res27901.html. Acesso em: 20 out. 2018.

DUTRA, R. M. Viabilidade técnico-econômica da energia eólica face ao novo marco regulatório do setor elétrico brasileiro. 2001. 309 f. Dissertação (Mestrado em Ciências e Planejamento energético) - Programa de Pós-graduação em Engenharia, Universidade Federal do Rio de Janeiro, Rio de Janeiro, 2001.

GANNOUM, E. Bons Ventos. Biomassabioenergia. 2018. Disponível em: https://www.biomassabioenergia.com.br/imprensa/bons-ventos/20180925-135540-u397. Acesso em: 28 out. 2020.

GAVINO, N. A. Energia eólica: uma análise dos incentivos à produção (2002-2009). 2011.115 f. Monografia (Bacharelado em Economia) - Instituto de Economia da Universidade Federal do Rio de Janeiro, Universidade Federal do Rio de Janeiro, Rio de Janeiro, 2011.

LEME, A. A. A reforma do setor elétrico no Brasil, Argentina e México: contrastes e perspectivas em debate. Rev. Sociol. Polit., Curitiba, v. 17, n. 33, p. 97-121, jun. 2009. Disponível em: http://www.scielo.br/scielo. php?script=sci_arttext\&pid=S010444782009000200008\&lng=en\&nrm=iso. Acesso em: 02 set. 2020.

LIMA, T.N. de A et al. Projeto de um protótipo de uma turbina eólica de eixo horizontal. 2015. 99 f. Monografia (Curso de Engenharia Mecânica da Escola Politécnica) - Faculdade de Engenharia Mecânica, Universidade Federal do Rio de Janeiro, 2015.

LUCRECIO, A. et al. Fontes de energia renováveis. 2010. Disponível em: https://universo.edu.br/extensao/page/2/. Acesso em: 29 jan. 2018.

MATARACA. Prefeitura Municipal. 2017. [Sem título]. Disponível em: http://mataraca.com/. Acessado em: 28 jun. 2017.

PACIFIC HYDRO. Parque Eólico Vale dos Ventos. 2018. Disponível em: http://www.pacifichydro.com.br. Acesso em: 20 out. 2020. 